$$
\begin{gathered}
\text { S sciendo } \\
\begin{array}{c}
\text { International Conference KNOWLEDGE-BASED ORGANIZATION } \\
\text { Vol. XXVII }
\end{array}
\end{gathered}
$$

\title{
REFLECTIONS ON TEACHING SPEAKING FOR EFL STUDENTS IN AN ONLINE ENVIRONMENT
}

\author{
Alina Gabriela NEGOESCU, Simona BOȘTINĂ-BRATU, Lucia Larissa MORAR \\ "Nicolae Bălcescu" Land Forces Academy, Sibiu, Romania \\ negoescu.alina@armyacademy.ro
}

\begin{abstract}
The health crisis due to the pandemic has greatly changed many aspects of our lives including the way we teach foreign languages. Online teaching has prevailed over the face-to-face one, and educators and learners alike had to adjust to this major shift. This article is meant to provide some of our findings based on our experience while teaching speaking on Moodle online platform. The first part discusses the benefits and the drawbacks of the online environment, then it presents some of the most important aspects of speaking, and in the end, it focuses on the challenges of online teaching while trying to enhance students' speaking skills. Speaking is one of the most desirable skills because it enables students to communicate effectively, and teaching this ability online has been challenging but also rewarding.
\end{abstract}

Keywords: speaking, online environment, accuracy, fluency

\section{Introduction}

The COVID-19 pandemic has changed education dramatically, as students and educators all over the world were forced to leave schools and universities and move into the online environment. Moreover, online classes and blended learning seem to be a constant reality in the educational process, the "new normal" as many scholars have named it, therefore we all need to adapt to this major change. We will refer to the online environment as being synchronous or asynchronous Internetbased learning environment that takes place via a learning platform such as Moodle, the one that we have used that includes all the resources needed to acquire knowledge.

2. Advantages and disadvantages of online learning environment

Online learning is without any doubt a significant component of the educational process and identifying the benefits and drawbacks of this new environment will help us create efficient strategies in order to deliver quality education to our students.

Teaching foreign languages is a complex process since it involves the development of the four competences, i.e. listening, reading, speaking and writing, and the mastery of these fundamental skills, that will help students in their future career, requires the use of the target language in different contexts and complex learning situations, and for these reasons, students are sometimes overwhelmed even in faceto-face classes, not to mention in online classes.

Some students need more guided learning and too much flexibility and autonomy in learning will confuse them more than help them. Students need to take charge, they have to be more disciplined and manage their time properly in order to be successful, due to the fact that the online learning environment is more dynamic, 
with more multi-dimensional learning tasks [1], such as online exercises, texts in different formats, presentations and videos and links to videos, etc.

Another drawback of the online learning environment is concerned with technical problems related to the internet connection or the malfunction of technical devices that can hinder the learning process. It is frustrating not to be able to attend a lesson because of the technical problems and this adds more anxiety to students and affects their motivation for learning, which is extremely important in learning a language.

We live in an age of technology, and technological advancements have definitely improved our lives in several domains, and education is no exception. There are obvious strengths to online language learning environment. For instance, we have noticed that one of the main advantages of the online foreign language classes is the fact that it reduces stress and thus increases learning performance for shy and introvert students, especially when it comes to speaking. Some of the students have mentioned that they prefer online classes because they do not have a teacher in front of them or colleagues to intimidate or judge them and that helps them increase their self-confidence and involvement in learning.

Online education is flexible in terms of time and mobile in terms of geography, which leads to greater autonomy in organizing the learning process. This is a great advantage for self-disciplined students that also know how to manage the learning time. It also meets the requirements of differentiation, if we consider the fact that each student solves his/her tasks at his/her own pace. At the same time solving online exercises is encouraging and motivating due to the fact that it provides instant feedback and explanations. Furthermore, they have the chance to repeat the exercises as many times as they need and go back to previous lessons and all these facilitate the learning process. Online language learning allows the use of a diverse package of methods and strategies that focus on the student, because we try to help the student understand.

Being connected to the Internet while teaching a foreign language is a great advantage especially when working on vocabulary and pronunciation. Educators can help students understand certain difficult items by providing links to pictures and videos or the pronunciation of some difficult words from the dictionary. Some videos are difficult to be entirely understood by the students, so they have the opportunity to watch them twice or as many times as they need. Having the Internet at their disposal is definitely comforting and reassuring for many students.

The fact that we had to rethink the content, to look for new methods and strategies of teaching and assessment that would be effective in the virtual environment enabled a transformation of the educational process with the help of technology, a transformation that meets the current requirements. However, in order to be successful in teaching an online language course, especially when teaching speaking, educators need to be well prepared and organized, and at the same time try to understand students and support them.

\section{Important aspects of speaking skills}

This section explores what students need to develop to be good speakers and what teaches need to take into account to enhance students' speaking skills. Sometimes we refer to someone who speaks fluently and uses the right words and grammatically correct utterances as being a good speaker, others would praise speakers that sound like natives, and in some contexts it is important to convince your audience. Therefore, speaking is a complex and dynamic process that involves many components such as fluency, grammar, vocabulary, and pronunciation. Furthermore, besides the linguistic competence that includes grammar, vocabulary and pronunciation, students 
need to understand and learn the sociolinguistic competence that means when and how to speak in a certain social context, make the appropriate comments or ask the right questions in an interaction. Even though speaking is closely related to the context, the speakers, and their experience and knowledge, and is also spontaneous most of the time, there are certain patterns that are repeated in certain situations and these can be learned.

Next, we will briefly discuss the key components of the oral discourse mentioned above. Some scholars organize the linguistic components in two main categories that are vital for speaking, namely accuracy and fluency. While accuracy refers to grammar, vocabulary and pronunciation, fluency refers to the ease with which someone speaks and includes the intonation, the speech rate, and the stress. When students acquire both accuracy and fluency in a foreign language they will become effective speakers, therefore teachers should design their speaking activities focusing on these components.

Fluency - is the ability to speak easily, at a reasonable fast speed and without interruptions or stops. Most often this is the sub-skill that is generally desired in academic or professional contexts because the ultimate objective is to be able to socialize and get your message across trying to avoid any misunderstanding. It is important that the speaker is understood by the listeners and do not stop to find words and phrases. When we focus on fluency it is better not to interrupt the students' flow by correcting every grammar, vocabulary or pronunciation error, because it may not be beneficial in the process of language acquisition. The importance of this type of activities is to use the language to communicate without too many hesitations. However, if teachers consider that they have to clarify something or the speaking activity is not going well they should intervene. We also agree with Harmer who believes that students should be consulted in whether they prefer being corrected during the speaking activity or after [2].

Grammar - is as important as fluency in developing speaking skills. Even though it is not an easy task, mastering grammar rules is rewarding since it enables learners to use the words correctly in a sentence and to use appropriate sentence structures needed to make themselves understood.

Vocabulary - refers to using the most appropriate words in the right contexts. Vocabulary is one of the first things students need to learn. Thus, acquiring words and phrases, or simply vocabulary, sufficient enough to express their ideas clearly is a vital objective in developing speaking and we would like to stress the importance of this activity. Students cannot communicate efficiently if their vocabulary is very limited, they would certainly pause and struggle to find words and sometimes use words and expressions that are not suitable in certain contexts. To sum up, without a good command of vocabulary students will not be able to speak effectively.

Pronunciation - refers to the way words are pronounced and the correct and clear production of the language when speaking. Pronunciation should not be disregarded as it plays an important role in avoiding miscommunication. Therefore, pronunciation exercises should not be overlooked when developing speaking skills.

Sociolinguistic competence - i.e. the culture of the people who speak the target language is incredibly important. Students should be able to distinguish and learn what is culturally and socially acceptable in the target language in various contexts.

To sum up, speaking in a foreign language is a complex process that comprises many components that we need to consider, and as a consequence, it is a lengthy process. Teachers must identify and be aware of the students' linguistic and sociolinguistic shortcomings and try to help them overcome these problems by providing the 
right resources and activities and at the same time make students enjoy this long journey. The online environment offers us plenty of resources to help students, such as the online exercises that we have seen that they enjoy, the videos and the recordings, etc.

\section{The challenges of developing speaking in an online environment}

According to Goh [3], speaking entails "dynamic interactions of mental, articulatory and social processes." In addition to the intellectual and social aspects of the speaking activities, developing students' speaking skills greatly depends on their intrinsic motivation and emotions. Neuro sciences have proved that many different parts of our brain are activated while speaking, more than doing any other language activity. Due to the fact that the body, the mind and the soul are connected to each other and "emotions are the key to the brain" [4] the emotional environment and the atmosphere that educators create during speaking classes is extremely important. There is a close link between learning and students' emotional system. Emotions send an input to the brain and depending on the type of emotion the brain receives it can respond positively or negatively. As a consequence, it would be a mistake to consider only the intellectual or the cognitive aspect of the speaking class. If the brain perceives danger, fear or anxiety that might come not only from the educator that constantly corrects every single mistake but also from the colleagues who make fun of his/her mistakes, - the educational process is definitely hindered. Thus, creating a relaxed atmosphere in which students feel safe and recognize the importance of the speaking activity is at least as significant as being prepared for the activity. If all these assertions are valid in the traditional face-to-face education, they apply even more so in the online environment. Creating a positive emotional climate is imperative in teaching speaking.
Another challenge of the online environment that we have encountered in teaching speaking is the lack of direct contact with the students. When we are face-to-face with the students, we can notice their body language and the nonverbal communication that allow us to instantly find out whether they understood or not, whether the method we have used has worked or not, etc., and we can adapt to the situation and fix these small shortcomings immediately. In the online learning environment, we cannot fully benefit from this advantage, especially if the students are not connected with a camera. We have conducted speaking activities with and without the camera and we have noticed that our students were a bit reluctant to turn on the camera for different reasons; some of them were shy and felt more comfortable and safer without the camera, and others were in the same room with members of their families. For introvert students, being able to speak without a camera was important as it helped them increase their self-confidence and involvement in speaking activities. However, we believe that teaching with a camera improves the speaking activities and helps in building relationships.

We believe this because we have had a rewarding experience with our students who participated in an online project on cultural awareness in times of COVID. Our students had to communicate via Moodle platform, connected with the web camera, with their fellow colleagues from the Military Academy in Lisbon and find out differences and similarities of the two academies and countries. The students were delighted to participate and due to the fact that they were highly motivated and the atmosphere was friendly and relaxed, their speaking abilities definitely improved together with their self-confidence.

Other difficulties that we have encountered both in online and face-to-face environment refer to the difficulty to break the ice and speak on a certain topic that sometimes 
comes from the fear of making mistakes and being criticised. There is a certain inhibition that some students show related to certain topics on which they do not have much to say, or they are inhibited because of their poor grammar and vocabulary.

\section{Conclusions}

Speaking is one of the most difficult skills to teach and to improve and it needs special attention in order to make students use the language accurately and fluently in appropriate social context. At the same time being able to effectively communicate in a foreign language is a must for students who want to be successful in their future careers. When it comes to speaking there are many challenges both in online and in face-toface teaching but with a good level of preparation and support we have noticed that students appreciated the opportunity to practice their speaking skills online, mostly because it proved to be useful - for example they could communicate with colleagues from another academy from abroad, - and they perceive it as a new, different and enriching experience.

\section{References List}

[1] Kuama S.; Intharaksa U. Is Online Learning Suitable for All English Language Students? [Internet]. PASAA Vol. 52 July - December 2016, Available from: http:// https://files.eric.ed.gov/fulltext/EJ1134684.pdf

[2] Harmer J. The Practice of English Language Teaching. Fourth Edition. Harlow: Pearson Education Limited, 2007.

[3] Goh C. Teaching Speaking. In: Renandya W.; Widodo H., editors. English Language Teaching Today. Switzerland: Springer International Publishing Switzerland; 2016. pp. 143-160.

[4] Pölzleitner E. Speaking and the Brain. In: Renner H.; Martinez M.; Klimek-Kowalska R. Editorial coordination. Guide for Efficient Teaching of Oral Skills. Austria: Stepan Druck, Ludwig Stepan GmbH \& Co KG; 2018. pp. 25-29. 